\title{
R Factor Transfer to Obligate Anaerobes from Escherichia coli
}

\author{
By SHARON J. BURT AND D. R. WOODS \\ Department of Microbiology, Rhodes University, Grahamstown 6I40, South Africa
}

(Received 25 June 1975; revised 31 October 1975)

\section{INTRODUCTION}

The environment in the mammalian gastrointestinal tract is mainly anaerobic, as demonstrated by the abundance of obligate anaerobic bacteria such as Bacteroides species (Finegold, 1970; Moore, Cato \& Holdeman, I969) and direct studies of intestinal gas composition (Askevold, 1956). Stallions \& Curtiss (1972), Moodie \& Woods (1973a) and Anderson (1975) have shown that both chromosomal and R factor transfer can occur between facultative Escherichia coli strains under stringent anaerobic conditions but this phenomenon has not been demonstrated in faecal obligate anaerobes. We have investigated $\mathrm{R}$ factor transfer in mating experiments between 30 faecal obligate anaerobes and between the anaerobes and known donor and recipient $E$. coli strains.

\section{METHODS}

Bacteria. The anaerobic glove box and techniques described by Moodie and Woods ( $1973 b$ ) were used to isolate 30 obligate anaerobic bacteria from human faecal samples. The anaerobes were isolated on blood agar media containing either kanamycin plus vancomycin or rifamycin plus vancomycin, which are selective for Bacteroides and Fusobacterium species, respectively (Finegold, Sugihara \& Sutter, 197I). All were Gram-negative, non-sporeforming rods, and their ability to grow in media containing desoxycholate $(0.1 \%, \mathrm{w} / \mathrm{v})$ and bile $(20 \%, \mathrm{w} / \mathrm{v})$ or desoxycholate alone was determined (Shimada, Sutter \& Finegold, 1970). The following abbreviations are used for genetic markers: amp (ampicillin), kan (kanamycin, nal (nalidixic acid), rif (rifamycin), tet (tetracycline) and van (vancomycin). Anaerobes that were $k a n^{\mathrm{r}}$ rif $^{\mathrm{s}} \operatorname{van}^{\mathrm{r}}$ and were able to grow in medium containing desoxycholate and bile were regarded as Bacteroides fragilis (strains I to I0) and those that were inhibited by desoxycholate, with or without bile, as Bacteroides spp. (strains I to 4). Anaerobes that were kan $^{\mathrm{s}}$ rif $^{\mathrm{r}}$ van $^{\mathrm{r}}$ and grew in medium containing desoxycholate in the presence or absence of bile were regarded as Fusobacterium spp. (strains I to 7) (Moore \& Holdeman, 1972). A fourth group included obligate anaerobes selected on antibiotic media but which could not be grouped in the above scheme (anaerobic strains I to 9). The obligate anaerobes were maintained under anaerobic conditions and tested routinely for aerobic growth. Two facultative $E$. coli strains were isolated from human faecal specimens: an R factor-containing strain $\mathrm{A}_{1}\left(a m p^{\mathrm{r}}\right)$ and a recipient strain B $\left(\right.$ nal $^{\mathrm{r}}$, rif $^{\mathrm{r}}$ ) (Moodie \& Woods, I973a).

Media. (Note: all percentage compositions are $w / v$ unless otherwise stated.) All media contained $0.4 \% \mathrm{Na}_{2} \mathrm{CO}_{3}$ and $0.05 \%$ cysteine-HCl. The liquid medium (BHI-S) and agar medium (BHIA-S) contained brain-heart infusion broth (Difco), supplemented with $0.005 \%$ haemin, $0.002 \%$ menadione and $0.5 \%$ yeast extract. Antibiotics were incorporated anaerobically in the agar medium at the following concentrations $\left(\mu \mathrm{g} \mathrm{ml}^{-1}\right)$ : ampicillin, 25; kanamycin, 1000; nalidixic acid, 30; rifamycin, 50; tetracycline, 50; vancomycin, $7 \cdot 5$. Incubation was at $37^{\circ} \mathrm{C}$. 
Table 1 . Minimal inhibitory concentrations of ampicillin for the obligate anaerobic bacteria used as recipients in the transfer experiments with the E coli $\mathrm{A}_{1}$ donor strain

M.i.c. of ampicillin
$(\mu \mathrm{g} / \mathrm{ml})$
0.8
1.6
$3 . \mathrm{I}$
$6 \cdot 2$
$\mathrm{I} 2.5$
25.0

$\begin{array}{lc}\begin{array}{l}\text { B. fragilis } \\ \text { strain no. }\end{array} & \begin{array}{c}\text { Bacteroides } \\ \text { spp. strain no. }\end{array} \\ 8 & - \\ -6,9 & - \\ 7 & 3 \\ 2,3,5,10 & 4 \\ \text { I, 4, } & \text { I, } 2\end{array}$

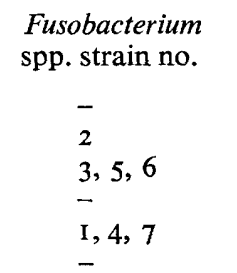

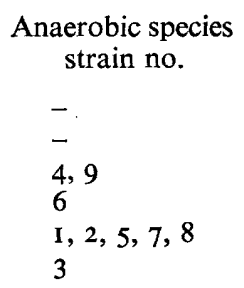

Antibiotic sensitivity tests. Antibiotic susceptibility patterns of the obligate anaerobes were determined by the sensitivity disc method (Sapico et al., 1972). Minimal inhibitory concentration (m.i.c.) values for ampicillin were determined by streaking broth cultures on BHIA-S medium containing doubling dilutions of ampicillin. The m.i.c. was defined as the lowest concentration which completely inhibited growth after incubation for $24 \mathrm{~h}$.

Resistance transfer experiments. Overnight cultures of the presumptive donor and recipient cultures were mixed in $4 \mathrm{ml}$ double-strength BHI-S medium. After incubation for a further $2 \mathrm{~h}$ exconjugants were selected by plating on BHIA-S agar media containing the appropriate antibiotics. In some experiments the obligate anaerobes were held at $50{ }^{\circ} \mathrm{C}$ for 20 min immediately before mating (Schell \& Glover, I966; Mojica-a \& Middleton, 197I). In all mating experiments each strain was plated separately on the selective media as a control for measuring the rate of spontaneous mutation. A further control was introduced in which the recipient culture was plated, in close proximity to the mating mixture, on a section of the same plate.

$\beta$-Lactamase assay. Overnight broth cultures of the strains under test were adjusted to a standard turbidity and harvested by centrifugation. Cells were resuspended in $0^{\circ} \mathrm{I} \mathrm{M}-$ phosphate buffer $\mathrm{pH} 5.9$ and treated for $5 \mathrm{~min}$ at $4{ }^{\circ} \mathrm{C}$ in an ultrasonic disintegrator (MSE) at maximum amplitude (Anderson \& Sykes, 1973). The disintegrated material was clarified by centrifugation at $35000 \mathrm{~g}$ for $30 \mathrm{~min}$ at $4{ }^{\circ} \mathrm{C}$. The supernatant was assayed for $\beta$-lactamase activity by measuring the rate of hydrolysis of ampicillin at $30{ }^{\circ} \mathrm{C}$ with the microiodometric method of Sykes \& Nordström (I972). The protein concentration of the supernatants was determined by the method of Lowry et al. (195I) as described by Chase \& Williams (1968) and the $\beta$-lactamase activity expressed as specific activity (rate of decolorization of starch-iodine $/ \mathrm{mg}$ protein at $3 \mathrm{C}^{\circ} \mathrm{C}$ ).

\section{RESULTS AND DISCUSSION}

\section{Intrageneric matings}

Transfer experiments between obligate anaerobes involved strains that were tet $^{\mathrm{r}}$ rif $^{\mathrm{s}}$ and strains that were tet $^{\mathrm{s}}$ rif $^{\mathrm{r}}$ with selection on medium containing tetracycline and rifamycin. No evidence of transfer of either marker was found.

\section{Intergeneric matings}

All anaerobes were $a m p^{\mathrm{s}}$, with m.i.c. values ranging from 0.8 to $25 \mu \mathrm{g} \mathrm{ml}^{-1}$ (Table I), and were $n a l^{\mathrm{r}}$. The E. coli donor was $a m p^{\mathrm{r}}\left(\mathrm{m}\right.$. i.c. $>\mathrm{IO}^{3} \mu \mathrm{g} \mathrm{ml}^{-1}$ ) and $n a l^{\mathrm{s}}$. Exconjugants were therefore sought on medium containing ampicillin and nalidixic acid. None were found when the anaerobes were not heated. However, 29 of the 30 anaerobes yielded $a m p^{\mathrm{r}}$ exconjugants 
Table 2. Transfer frequencies from $E$. coli donor strain $\left(a m p^{\mathbf{r}} n a l^{\mathrm{s}}\right)$ to obligate anaerobic recipient bacteria ( $\mathrm{amp}^{\mathrm{s}}$ nal $\mathrm{l}^{\mathrm{r}}$ ) after heating the recipients at $50^{\circ} \mathrm{C}$ for $20 \mathrm{~min}$

Frequencies were calculated as the number of $a m p^{r} n a l^{r}$ exconjugants/donor cell added.

\begin{tabular}{|c|c|c|c|}
\hline Anaerobes & Strain no. & $\begin{array}{c}10^{-6} \times \text { transfer } \\
\text { frequency }\end{array}$ & $\begin{array}{l}\text { Stability } \\
\text { exconjugan } \\
\text { on subcult }\end{array}$ \\
\hline \multirow[t]{10}{*}{ B. fragilis } & I & 100 & + \\
\hline & 2 & 100 & + \\
\hline & 3 & I2 & + \\
\hline & 4 & 500 & + \\
\hline & 5 & I I & + \\
\hline & 6 & 39 & - \\
\hline & 7 & 210 & - \\
\hline & 8 & 39 & - \\
\hline & 9 & 430 & - \\
\hline & 10 & 0 & \\
\hline \multirow[t]{4}{*}{ Bacteroides spp. } & I & 250 & + \\
\hline & 2 & 410 & + \\
\hline & 3 & 280 & - \\
\hline & 4 & 100 & - \\
\hline \multirow[t]{7}{*}{ Fusobacterium spp. } & I & 100 & + \\
\hline & 2 & 100 & + \\
\hline & 3 & 100 & + \\
\hline & 4 & 380 & + \\
\hline & 5 & 100 & + \\
\hline & 6 & 100 & + \\
\hline & 7 & 25 & - \\
\hline \multirow[t]{9}{*}{ Anaerobic spp. } & I & 43 & + \\
\hline & 2 & 100 & + \\
\hline & 3 & 100 & + \\
\hline & 4 & 100 & + \\
\hline & 5 & 100 & + \\
\hline & 6 & 100 & + \\
\hline & 7 & 50 & - \\
\hline & 8 & I & - \\
\hline & 9 & 100 & - \\
\hline
\end{tabular}

at frequencies $>\mathrm{I} \times \mathrm{I}^{6} /$ donor cell after heat treatment (Table 2). No spontaneous $a m p^{\mathrm{r}}$ mutants were found on control plates. All $a m p^{\mathrm{r}}$ exconjugants were obligate anaerobes and either $k a n^{\mathrm{r}}, v a n^{\mathrm{r}}$ or $r i f^{\mathrm{r}}$, in agreement with their susceptibility patterns before mating. The changes in antibiotic resistance patterns were therefore not due to mutation of the donor facultative $E$. coli strain or to contamination.

Since ampicillin resistance in the $E$. coli $\mathrm{R}$ factor donor strain is due to the production of $\beta$-lactamase, the production of $\beta$-lactamase by five of the obligate anaerobic $a m p^{\mathrm{r}}$ exconjugant strains and their parent $a m p^{\mathrm{s}}$ strains was determined and compared with the $\beta$-lactamase activity of the $a m p^{\mathrm{s}} E$. coli $\mathrm{B}$ recipient and an $a m p^{\mathbf{r}}$ exconjugant of this strain (Table 3 ). The levels of $\beta$-lactamase activity of the anaerobic $a m p^{\mathrm{s}}$ recipient strains and the $a m p^{\mathrm{s}} E$. coli $\mathrm{B}$ recipient strain were low (between 0.007 and 0.035). All the exconjugant $a m p^{\mathbf{r}}$ strains showed a statistically significant increase in $\beta$-lactamase activity. This is further evidence that the $a m p^{\mathrm{r}}$ exconjugants received the $a m p^{\mathrm{r}} \mathrm{R}$ factor by conjugation from the $E$. coli donor strain and that their resistance was due to enzymic destruction of ampicillin rather than to an increase in intrinsic resistance.

Exconjugants from ten of the obligate anaerobes isolated on the nalidixic acid plus 
Table 3. $\beta$-Lactamase activity of the amp recipient strains and the amp ${ }^{\mathrm{r}}$ exconjugant strains obtained after mating with the E. coli amp $p^{\mathrm{r}} R$ factor-containing strain

Specific activity of $\beta$-lactamase is expressed as the rate of decolorization of starch-iodine/mg protein.

$\begin{array}{lcc} & \overbrace{\text { Recipient } a m p^{s}}^{\text {Specific activity of } \beta \text {-lactamase }} \\ \text { Bacterial strain } & 0.033 & 6.612 \\ \text { B. fragilis I } & 0.007 & 0.255 \\ \text { B. fragilis 2 } & 0.022 & 0.636 \\ \text { B. fragilis 3 } & 0.009 & 0.162 \\ \text { Bacteroides spp. I } & 0.035 & 0.85 \mathrm{I} \\ \text { Fusobacterium spp. I } & 0.01 \mathrm{I} & \mathrm{I} \cdot 2 \mathrm{I} 3 \\ \text { E. coli } \mathrm{B} & & \end{array}$

ampicillin selective medium were unstable on subculture on to medium containing these two antibiotics (Table 2), whereas those from 19 other strains were stable. The average rate of segregation of $a m p^{\mathrm{s}}$ in three of the stable $a m p^{\mathrm{r}}$ strains varied between 0.50 and 0.94/cell/ generation. Three stable anaerobic exconjugants $\left(a m p^{\mathrm{r}} n a l^{\mathrm{r}}\right.$ rif $\left.\mathrm{s}\right)$ were tested for their ability to retransfer the $a m p^{\mathrm{r}}$ marker in mating experiments with I I obligate anaerobes $\left(a m p^{\mathrm{s}} n a l^{\mathrm{r}}\right.$ $\left.r i f^{\mathrm{r}}\right)$ and with the $E$. coli $\mathrm{B}$ recipient strain $\left(a m p^{\mathrm{s}} n a l^{\mathrm{r}} r i f^{\mathrm{r}}\right)$. No $a m p^{\mathrm{r}} n a l^{\mathrm{r}}$ rif $^{\mathrm{r}}$ exconjugants were isolated.

It was possible that the ten exconjugants that were unstable on subculture, were obtained as a result of the donor strain producing $\beta$-lactamase, which reduced the concentration of ampicillin in the selective medium to a level that failed to inhibit the recipient. This is unlikely, however, since the recipient control cultures failed to produce colonies when they were plated on separate sections of the same plate and in close proximity to mating mixtures which produced confluent growth.

Our results show that $\mathrm{R}$ factor transfer from E. coli to B. fragilis, Bacteroides spp., Fusobacterium spp. and other faecal obligate anaerobic bacteria is possible after heat treatment of the recipients, which presumably inhibits restriction systems of the anaerobes, as in E. coli (Schell \& Glover, I966) and in Salmonella typhimurium (Mojica-a \& Middleton, 197I). The anaerobic exconjugants segregated $a m p^{\mathrm{s}}$ cells at a frequency characteristic of cytoplasmic genes and were unable to retransfer the $a m p^{\mathbf{r}}$ marker. No transferable resistance factors were detected in 14 Bacteroides strains, seven Fusobacterium strains and nine other obligate anaerobic strains, all of which were resistant to a number of antibiotics. This is in agreement with the study of ten Bacteroides strains reported by Anderson \& Sykes (I973). Failure to detect $\mathrm{R}$ factor transfer to obligate anaerobes under normal conditions suggests that $\mathrm{R}$ factor-mediated antibiotic resistance in anaerobes is not clinically significant. Nevertheless, our results show that $\mathbf{R}$ factor transfer to anaerobes is possible and there may be other more natural conditions which might enhance $\mathrm{R}$ factor transfer to anaerobes under clinical conditions.

This work was supported by a research grant from the South African Medical Research Council. 


\section{REFERENCES}

Anderson, J. D. (I975). Factors that may prevent transfer of antibiotic resistance between Gram-negative bacteria in the gut. Journal of Medical Microbiology 8, 83-88.

Anderson, J. D. \& Sykes, R. B. (1973). Characterisation of a $\beta$-lactamase obtained from a strain of Bacteriodes fragilis resistant to $\beta$-lactam antibiotics. Journal of Medical Microbiology 6, 20I-206.

AskeVold, F. (1956). Investigations on the influence of diet on the quantity and composition of intestinal gas in humans. Scandinavian Journal of Clinical and Laboratory Investigation 8, 87-94.

Chase, M. W. \& Williams, C. A. (1968). Protein analysis. In Methods in Immunology and Immunochemistry, vol. 2, pp. 249-282, Edited by C. A. Williams and M. W. Chase. New York: Academic Press.

FineGold, S. M. (1970). Gram-negative anaerobic rods - Bacteroidaceae. In Gradwohl's Clinical Laboratory Methods and Diagnosis, 7th edn, pp. 1353-1365. Edited by S. Frankel. St Louis: C. V. Mosby.

Finegold, S. M., Sugihara, P. T. \& Sutter, V. L. (I97I). Isolation of anaerobes from humans. In Isolation of Anaerobes, pp. 99-I08. Edited by D. A. Shapton and R. G. Board. London: Academic Press.

Lowry, O. H., Rosebrough, N. J., Farr, A. L. \& Randall, R. J. (I95I). Protein measurement with the Folin phenol reagent. Journal of Biological Chemistry 193, 265-275.

MoJicA-A, T. \& Middleton, R. B. (I97I). Fertility of Salmonella typhimurium crosses with Escherichia coli. Journal of Bacteriology 108, II $6 \mathrm{I}-1 \mathrm{I} 67$.

Moodie, H. L. \& Woods, D. R. (I973a). Anaerobic R factor Transfer in Escherichia coli. Journal of General Microbiology 76, 437-440.

Moodie, H. L. \& Woods, D. R. ( $1973 b)$. Isolation of obligate anaerobic faecal bacteria using an anaerobic glove cabinet. South African Medical Journal 47, I739-1742.

Moore, W. E. C., Cato, E. P. \& Holdeman, L. V. (1969). Anaerobic bacteria of the gastrointestinal flora and their occurrence in clinical infections. Journal of Infectious Diseases II9, 64I-649.

Moore, W. E. C. \& Holdeman, L. V. (I972). Identification of anaerobic bacteria. American Journal of Clinical Nutrition 25, I306-I3I3.

SAPICO, F. L., Kwok, Y., SutTer, V. L. \& FINEgold, S. M. (1972). Standardised antimicrobial disc susceptibility testing of anaerobic bacteria: in vitro susceptibility of Clostridium perfringens to nine antibiotics. Antimicrobial Agents and Chemotherapy 2, 320-325.

SCHell, J. \& Glover, S. W. (I966). The effect of heat on host-controlled restriction of phage $\lambda$ in Escherichia coli $\mathrm{K}(\mathrm{PI})$. Journal of General Microbiology 45, 6I-72.

Shimada, K., Sutter, V. L. \& Finegold, S. M. (1970). Effect of bile and desoxycholate on Gram-negative anaerobic bacteria. Applied Microbiology 20, 737-741.

Stallions, D. R. \& Curtiss, R. (1972). Bacterial conjugation under anaerobic conditions. Journal of Bacteriology III, 294-295

Sykes, B. R. \& Norström, K. (1972). Microiodometric determination of $\beta$-lactamase activity. Antimicrobial Agents and Chemotherapy 2, 94-99. 